Check for updates

MRC Biostatistics Unit, School of Clinical Medicine, University of Cambridge, Cambridge, UK

2 Immunodeficiency Centre of Wales, University Hospital Wales, Cardiff, UK

3 Clinical Pharmacology and Therapeutics Section, Institute of Medical and Biomedical Education and Institute for Infection and Immunity, St George's, University of London, London, UK

Correspondence to: 5 Burgess sb452@medschl.cam.ac.uk

Cite this as: BMJ 2020;370:m3364 http://dx.doi.org/10.1136/bmj.m3364 Published: 03 September 2020

\section{Are we underestimating seroprevalence of SARS-CoV-2?}

\author{
Current antibody tests fail to identify people who had mild infections \\ Stephen Burgess, ${ }^{1}$ Mark J Ponsford, ${ }^{2}$ Dipender Gill ${ }^{3}$
}

Testing for severe acute respiratory coronavirus 2 (SARS-CoV-2), which causes covid-19, is complex and politically sensitive. Seroprevalence studies use antibodies as markers of pathogen exposure to estimate the proportion of the population that has been infected.

Considerable variation has been observed in the results of SARS-CoV-2 seroprevalence studies. ${ }^{1} \mathrm{~A}$ recent survey in Spain suggested that a small fraction of the population was seropositive, despite the country being severely affected by the virus. ${ }^{2}$ However, within-individual variation has been observed in immune responses to viral exposure, particularly in those with mild or asymptomatic disease. For example, a pilot study from the Karolinska Institute found the percentage of people mounting T cell responses after mild covid-19, asymptomatic disease, or exposure to infected family members, consistently exceeded the percentage mounting detectable IgG serological responses against the virus. ${ }^{3}$ Such discordant results could have major implications for epidemiological modelling of disease transmission and herd immunity.

Seroepidemiological studies may underestimate the true seroprevalence of SARS-CoV-2 for several reasons. Accuracy demands the use of an assay sensitive enough to reliably detect antibody responses to mild infection across different post-exposure scenarios. The selection of target antigen is critical, with recent data showing that the trimeric spike glycoprotein offers superior detection to the nucleocapsid in people with low level antibody responses. ${ }^{4}$ Of the 24 serological diagnostic tests that the FDA initially authorised for emergency use, six consider only the nucleocapsid, including high throughput tests in widespread use.

The nature of the pandemic means that tests have been evaluated mostly on people who experienced severe covid-19 symptoms. ${ }^{5}$ Recent evidence describes a clear link between the magnitude of serological responses and severity of illness. ${ }^{46}$ This implies that unless assay performance is also assessed in mild and convalescent cases, the threshold for a positive result may be too high, resulting in missed community cases.

Other problems with test calibration include the effect of demographic factors such as age, sex, and ethnicity on antibody responses and hence assay results, ${ }^{7}$ and the effect of timing, since early testing before seroconversion may result in false negative results. Preliminary reports showing rapid decline in virus specific IgG levels suggest that testing too late may also miss cases. ${ }^{8}$
Test performance is also influenced by the choice of antibody. Of the FDA authorised tests, most detect only IgG and IgM antibodies, the dominant components of the bloodborne antibody response. But IgA also has an important role in the immune response to respiratory tract infections and seems immunologically relevant in covid-19, particularly in asymptomatic people..$^{910}$

\section{Look for $\lg A$}

SARS-CoV-2 enters cells by interacting with host proteins expressed in the respiratory tract, cornea, and gastrointestinal tract. ${ }^{11} \mathrm{IgA}$ is the predominant immunoglobulin expressed at these mucosal surfaces, ${ }^{12}$ and IgA responses with neutralising capability are described for several viral pathogens. ${ }^{910} 13$ IgA antibodies specific to SARS-CoV-2 have now been detected in various biological specimens, including serum, saliva, and breast milk. ${ }^{414} 15$

Serum IgA antibody responses may be detectable earlier than IgG and IgM responses ${ }^{1617}$ and can persist for at least 38 days in hospital patients recovering from covid-19. ${ }^{18}$ This is consistent with a recent Cochrane review, which found that IgA based serological testing had greater sensitivity than other methods. ${ }^{5}$ A recent seroprevalence survey of 1473 residents ( $79 \%$ of the local population) in Ischgl, Austria, using a combined IgG and IgA approach found SARS-CoV-2 antibodies in $42.4 \%$ of those tested, far higher than rates in previous population based surveys of other infection hotspots. ${ }^{19}$ Similarly, IgA antibodies were detected in $11 \%$ of 1862 people sampled from the general population in Luxembourg, whereas IgG antibodies were found in only $1.9 \% .^{20}$

Finally, mucosal and bloodborne immune responses may provide complementary information crucial for accurate assessment of viral exposure in both individuals and populations. In a cross sectional study of UK healthcare workers, combined IgG, IgA, and IgM testing for SARS-Cov-2 spike protein in saliva samples identified $15 \%$ of participants as positive despite a negative serum test result. ${ }^{4}$

In conclusion, current seroprevalence studies may fail to detect people who have had mild covid-19. Standardised approaches are required so seroprevalence estimates are comparable. Specific consideration should be given to the selection of the SARS-CoV-2 antigen in diagnostic assays, calibration of assay thresholds, the breadth of the antibody response, and the role of mucosal antibody responses. Application of these principles in future seroprevalence surveys may offer more accurate insight into the population dynamics of covid-19 and 


\section{help inform epidemiological modelling strategies and public health policy.}

Competing interests: We have read and understood the BMJ policy on declaration of interests and declare the following interests: DG is employed part time by Novo Nordisk, unrelated to the submitted work.

Provenance and peer review: Not Commissioned; externally peer reviewed.

We thank Adrian M Shields, Tariq El-Shanawany, Peter Willeit, Alex G Richter, and Stephen Jolles for reading and commenting on this article.

1 Ioannidis ). The infection fatality rate of COVID-19 inferred from seroprevalence data. medRxiv 2020:2020.2005.2013.20101253. [Preprint.] doi: 10.1101/2020.05.13.20101253

2 Pollán M, Pérez-Gómez B, Pastor-Barriuso R, etalENE-COVID Study Group. Prevalence of SARS-CoV-2 in Spain (ENE-COVID): a nationwide, population-based seroepidemiological study. Lancet 2020;396:535-44 . doi: 10.1016/S0140-6736(20)31483-5 pmid: 32645347

3 Sekine T, Perez-Potti A, Rivera-Ballesteros 0, etalRobust T cell immunity in convalescent individuals with asymptomatic or mild COVID-19.Cell 2020. doi: 10.1016/j.cell.2020.08.017.

4 Faustini SE, Jossi SE, Perez-Toledo M, et al. Detection of antibodies to the SARS-CoV-2 spike glycoprotein in both serum and saliva enhances detection of infection. medRxiv 2020.2006.2016.20133025. [Preprint.] doi: 10.1101/2020.2006.2016.20133025

5 Deeks JJ, Dinnes J, Takwoingi Y, etalCochrane COVID-19 Diagnostic Test Accuracy Group. Antibody tests for identification of current and past infection with SARS-CoV-2. Cochrane Database Syst Rev 2020;6:.pmid: 32584464

6 Long Q-X, Tang X-J, Shi Q-L, etal. Clinical and immunological assessment of asymptomatic SARS-CoV-2 infections. Nat Med 2020;26:1200-4. doi: 10.1038/s41591-020-0965-6 pmid: 32555424

7 Scully EP, Haverfield J, Ursin RL, Tannenbaum C, Klein SL. Considering how biological sex impacts immune responses and COVID-19 outcomes. Nat Rev Immunol 2020;20:442-7. doi: 10.1038/s41577-020-0348-8 pmid: 32528136

8 Ibarrondo FJ, Fulcher JA, Goodman-Meza D, etal. Rapid decay of anti-SARS-CoV-2 antibodies in persons with mild covid-19. N Engl J Med 2020. [Epub ahead of print.]. doi: 10.1056/NEJMc2025179 pmid: 32706954

9 Habibi MS, Jozwik A, Makris S, etalMechanisms of Severe Acute Influenza Consortium Investigators. Impaired antibody-mediated protection and defective IgA B-cell memory in experimental infection of adults with respiratory syncytial virus. Am J Respir Crit Care Med 2015;191:1040-9. doi: 10.1164/rccm.201412-22560C pmid: 25730467

10 Krammer F. The human antibody response to influenza A virus infection and vaccination. Nat Rev Immunol 2019;19:383-97. doi: 10.1038/s41577-019-0143-6 pmid: 30837674

11 Sungnak W, Huang N, Bécavin C, etalHCA Lung Biological Network. SARS-CoV-2 entry factors are highly expressed in nasal epithelial cells together with innate immune genes. Nat Med 2020;26:681-7. doi: 10.1038/s41591-020-0868-6 pmid: 32327758

12 Corthésy B. Multi-faceted functions of secretory IgA at mucosal surfaces. Front Immunol 2013;4:185. doi: 10.3389/fimmu.2013.00185 pmid: 23874333

13 Suzuki T, Kawaguchi A, Ainai A, etal. Relationship of the quaternary structure of human secretory IgA to neutralization of influenza virus. Proc Natl Acad Sci U S A 2015;112:7809-14. doi: 10.1073/pnas.1503885112 pmid: 26056267

14 Amanat F, Stadlbauer D, Strohmeier S, etal. A serological assay to detect SARS-CoV-2 seroconversion in humans. Nat Med 2020;26:1033-6. doi: 10.1038/s41591-020-0913-5 pmid: 32398876

15 Fox A, Marino J, Amanat F, et al. Evidence of a significant secretory-lgA-dominant SARS-CoV-2 immune response in human milk following recovery from COVID-19. medRxiv 2020:2020.2005.2004.20089995. [Preprint.] doi: 10.1101/2020.2005.2004.20089995

$16 \mathrm{Ma} \mathrm{H}$, Zeng W, He H, etal. Serum IgA, IgM, and IgG responses in COVID-19. Cell Mol Immunol 2020;17:773-5. doi: 10.1038/s41423-020-0474-z pmid: 32467617

17 Guo L, Ren L, Yang S, etal. Profiling Early Humoral Response to Diagnose Novel Coronavirus Disease (COVID-19). Clin Infect Dis 2020;71:778-85. doi: 10.1093/cid/ciaa310 pmid: 32198501

18 Padoan A, Sciacovelli L, Basso D, etal. IgA-Ab response to spike glycoprotein of SARS-CoV-2 in patients with COVID-19: A longitudinal study. Clin Chim Acta 2020;507:164-6. doi: 10.1016/j.cca.2020.04.026 pmid: 32343948

19 Knabl L, Mitra T, Kimpel J, et al. High SARS-CoV-2 seroprevalence in children and adults in the Austrian ski resort Ischgl. medRxiv 2020 2020.2008.2020.20178533. [Preprint.] doi: 10.1101/2020.2008.2020.20178533

20 Snoeck CJ, Vaillant M, Abdelrahman T, et al. Prevalence of SARS-CoV-2 infection in the Luxembourgish population: the CON-VINCE study. medRxiv2020:2020.2005.2011.20092916. [Preprint.] doi: 10.1101/2020.2005.2011.20092916.

This article is made freely available for use in accordance with BMJ's website terms and conditions for the duration of the covid-19 pandemic or until otherwise determined by BMJ. You may use, download and print the article for any lawful, non-commercial purpose (including text and data mining) provided that all copyright notices and trade marks are retained. 